\title{
Breast-feeding in South Korea: factors influencing its initiation and duration
}

Woojin Chung ${ }^{1}$, Hanjoong $\mathrm{Kim}^{2, *}$ and Chung-Mo $\mathrm{Nam}^{2}$

'Graduate School of Public Health, Yonsei University, 134 Shinchon-dong, Seodaemun-gu, Seoul 120-752, South Korea: ${ }^{2}$ Department of Preventive Medicine and Public Health, Yonsei University College of Medicine, Seoul, South Korea

Submitted 9 August 2006: Accepted 28 March 2007: First published online 8 August 2007

\begin{abstract}
Objective: To investigate factors influencing the practices of partial breast-feeding (PBF) and exclusive breast-feeding (EBF).

Design: A national, cross-sectional survey was conducted among married women aged 15-49 years from May to August 2003.

Setting: South Korea.

Subjects: A total of 865 mothers answered questions regarding the feeding practices of their youngest baby, born between January 2001 and May 2003.

Results: The initiation rates of $\mathrm{PBF}$ and $\mathrm{EBF}$ were $81 \%$ and $63 \%$, respectively. However, the median durations of PBF and EBF were very short: 12 and 8 weeks, respectively. According to stepwise logistic and Cox regression analyses, the more prenatal care women received, the more likely they were to initiate PBF and EBF but the less likely to continue EBF. Delivery by Caesarean section decreased the initiation of PBF and EBF. The mother's education level and employment status before marriage, the amount of prenatal care, delivery method and baby's status at birth affected breast-feeding initiation, whereas the amount of prenatal care influenced breast-feeding duration.

Conclusion: To promote breast-feeding, education and campaigning on the importance of continued breast-feeding should be provided to the general public, particularly to health workers in maternity units.
\end{abstract}

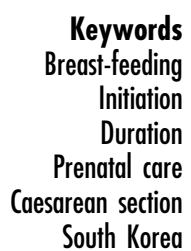

South Korea
Despite the increased appreciation of infants in a society with a very low fertility rate (total fertility rate was 1.08 in $2005)^{1}$, many South Korean infants have been excluded from the benefits of breast-feeding. The proportion of mothers who breast-feed infants exclusively declined from $59.0 \%$ in 1985 to $16.5 \%$ in $2003^{2}$. Moreover, because South Korea shows a high rate of delivery by Caesarean section $(38.9 \% \text { in } 2003)^{3}$, this provides a good opportunity to explore a potential association between breastfeeding and delivery by Caesarean section. However, no in-depth study using a dataset obtained from a national survey on factors affecting breast-feeding initiation and duration in South Korea has ever been published in an international journal. Furthermore, studies of breastfeeding in South Korea have used definitions for breastfeeding that differ from international criteria. For example, in South Korea, the breast-feeding rate has been defined as the proportion of mothers who breast-feed infants or breast-feed infants while giving complementary food $^{4-6}$.

The aim of the present study was to identify the factors influencing a mother's breast-feeding initiation and duration in South Korea for both partial and exclusive breast-feeding.

\section{Methods}

South Korea has conducted national surveys regarding fertility and family health periodically since 1964. The 2003 survey used in this study was the 19th survey conducted and the most recent one available. The survey was conducted from 12 May to 31 August 2003 by the Korea Institute for Health and Social Affairs. Through individual interviews, 8890 women between the ages of 15 and 49 years provided information on their marriage, pregnancy and birth histories and other individual characteristics. Among the women, 865 mothers had given birth between January 2000 and May 2003 and answered questions regarding the feeding practices of their youngest baby born during this period ${ }^{2}$.

In this study, exclusive breast-feeding (EBF) was defined as feeding by breast milk only with no other liquids or solids with the exception of drops or syrups 
consisting of vitamins, mineral supplements or medicines $^{7}$. Partial breast-feeding (PBF) was defined as any kind of breast-feeding, including partial or supplemented and EBF.

Each breast-feeding initiation and duration was considered a dependent variable. Characteristics considered to affect breast-feeding practice were regarded as independent variables: mother's age, education level of the parents, residence, mother's employment status before marriage, baby's sex, baby's birth weight, baby's status at birth, amount of prenatal care a mother had received, delivery institution, baby's birth order and delivery method.

This study concerned PBF and EBF separately, and, for each, a two-part analysis was conducted. For the first part, factors influencing a mother's initiation of breast-feeding were investigated. The significance of the associations between breast-feeding practice and independent variables was explored through $\chi^{2}$ tests. Then, stepwise multivariate logistic regression analyses were conducted to calculate the odds ratios (ORs) for each independent variable for breast-feeding.

The second part of the analysis explored factors affecting a mother's breast-feeding duration. The main dependent variable was the duration (weeks) from the start of breast-feeding to its cessation among mothers who had reported at least some breast-feeding. Since not all women had completed breast-feeding at the time of the survey, the survival analysis was conducted as follows. First, the log-rank test was used to test whether or not 'risk' of cessation of breast-feeding varied across categories for an independent variable; second, using stepwise multivariate Cox regression analysis, risk factors for stopping breast-feeding were presented as hazard ratios (HRs). Analyses were performed using SAS software (SAS Institute) and a probability level of $P<0.05$ was considered significant.

\section{Results}

In this sample study, out of 865 mothers, 703 mothers (81.3\%) had initiated PBF whereas 546 mothers (63.1\%) had initiated EBF. Among mothers who began breastfeeding, 43 women had not completed PBF and 21 had not completed EBF at the time of the survey.

\section{Partial breast-feeding}

Table 1 presents the characteristics of the respondents by breast-feeding status. The non-PBF mothers tended to be less educated, resided in rural areas, had a blue-collar job before marriage, gave birth prematurely, had less prenatal

Table 1 Characteristics of respondents for partial and exclusive breast-feeding

\begin{tabular}{|c|c|c|c|c|c|c|c|}
\hline \multirow[b]{2}{*}{ Characteristic } & \multirow[b]{2}{*}{ Non-PBF } & \multirow[b]{2}{*}{ PBF } & \multicolumn{2}{|c|}{ Initiation (\%) } & \multirow[b]{2}{*}{ Overall } & \multicolumn{2}{|c|}{$\begin{array}{c}\text { Duration } \\
\text { (weeks, median) }\end{array}$} \\
\hline & & & Non-EBF & EBF & & PBF & EBF \\
\hline Mother's education & & & & & & & \\
\hline$\leq$ Senior high school & 70.4 & 53.5 & 58.0 & 55.9 & 56.7 & 12.0 & 8.0 \\
\hline$>$ Senior high school & 29.6 & 46.5 & 42.0 & 44.1 & 43.3 & 12.0 & 12.0 \\
\hline Father's education & & & & & & & \\
\hline$\leq$ Senior high school & 58.0 & 46.5 & 50.0 & 48.0 & 48.7 & 12.0 & 12.0 \\
\hline$>$ Senior high school & 42.0 & 53.5 & 50.0 & 52.0 & 51.3 & 12.0 & 8.0 \\
\hline Residence & & & & & & & \\
\hline Metropolis & 34.6 & 45.2 & 40.4 & 44.9 & 43.3 & 12.0 & 12.0 \\
\hline Small city & 45.0 & 41.0 & 42.0 & 41.6 & 41.7 & 8.0 & 8.0 \\
\hline Rural area & 20.4 & 13.8 & 17.6 & 13.5 & 15.0 & 8.0 & 8.0 \\
\hline Mother's employment status before marriage & & & & & & & \\
\hline No job or white-collar job & 64.2 & 79.0 & 71.8 & 78.8 & 76.2 & 12.0 & 8.0 \\
\hline Blue-collar job & 35.8 & 21.0 & 28.2 & 21.2 & 23.8 & 12.0 & 12.0 \\
\hline Baby's status at birth & & & & & & & \\
\hline Mature & 82.7 & 91.3 & 86.8 & 91.4 & 89.7 & 11.0 & 8.0 \\
\hline Premature & 17.3 & 8.7 & 13.2 & 8.6 & 10.3 & 12.0 & 12.0 \\
\hline Amount of prenatal care & & & & & & & ** \\
\hline$\leq 10$ & 42.0 & 29.9 & 36.7 & 29.5 & 32.1 & 12.0 & 20.0 \\
\hline$>10$ & 58.0 & 70.1 & 63.3 & 70.5 & 67.9 & 12.0 & 8.0 \\
\hline Baby's birth order & & & & & & & \\
\hline Second or higher & 66.7 & 57.9 & 61.4 & 58.4 & 59.5 & 12.0 & 12.0 \\
\hline First & 33.3 & 42.1 & 38.6 & 41.6 & 40.5 & 8.0 & 8.0 \\
\hline Delivery method & & & & & & * & * \\
\hline Normal delivery & 48.1 & 63.0 & 54.6 & 63.6 & 60.2 & 12.0 & 12.0 \\
\hline Caesarean section & 51.9 & 37.0 & 45.4 & 36.4 & 39.8 & 8.0 & 8.0 \\
\hline Total & 18.7 & 81.3 & 36.9 & 63.1 & 100.0 & 12.0 & 8.0 \\
\hline$N$ & 162 & 703 & 319 & 546 & 865 & 703 & 546 \\
\hline
\end{tabular}

PBF - partial breast-feeding; EBF - exclusive breast-feeding.

${ }^{\star} P<0.05,{ }^{\star \star} P<0.01$ ( $\chi^{2}$ test for initiation, log-rank test for duration); insignificant characteristics are not shown. 
Table 2 Factors influencing the initiation and duration of partial and exclusive breast-feeding (stepwise logistic and Cox regression analyses)

\begin{tabular}{|c|c|c|c|c|}
\hline \multirow[b]{2}{*}{ Characteristic } & \multicolumn{2}{|c|}{ Initiation } & \multicolumn{2}{|c|}{ Duration } \\
\hline & $\begin{array}{c}\text { PBF } \\
\text { OR }(95 \% \mathrm{Cl})\end{array}$ & $\begin{array}{c}\text { EBF } \\
\text { OR }(95 \% \mathrm{Cl})\end{array}$ & $\begin{array}{c}\text { PBF } \\
\mathrm{HR}(95 \% \mathrm{Cl})\end{array}$ & $\begin{array}{c}\text { EBF } \\
\mathrm{HR}(95 \% \mathrm{Cl})\end{array}$ \\
\hline \multicolumn{5}{|l|}{ Mother's education } \\
\hline$\leq$ Senior high school & 1.00 (referent) & & & \\
\hline$>$ Senior high school & $1.64(1.11-2.44)^{\star}$ & & & \\
\hline \multicolumn{5}{|c|}{ Mother's employment status before marriage } \\
\hline No job or white-collar job & 1.00 (referent) & 1.00 (referent) & & \\
\hline Blue-collar job & $0.53(0.36-0.79)^{\star *}$ & $0.68(0.49-0.94)^{\star}$ & & \\
\hline \multicolumn{5}{|l|}{ Baby's status at birth } \\
\hline Mature & 1.00 (referent) & 1.00 (referent) & & \\
\hline Premature & $0.52(0.31-0.86)^{\star}$ & $0.68(0.44-1.07)$ & & \\
\hline \multicolumn{5}{|l|}{ Amount of prenatal care } \\
\hline$\leq 10$ & 1.00 (referent) & 1.00 (referent) & & 1.00 (referent) \\
\hline$>10$ & $1.65(1.14-2.39)^{\star \star}$ & $1.38(1.03-1.87)^{\star}$ & & $1.24(1.03-1.50)^{*}$ \\
\hline \multicolumn{5}{|l|}{ Delivery method } \\
\hline Normal delivery & 1.00 (referent) & 1.00 (referent) & 1.00 (referent) & 1.00 (referent) \\
\hline Caesarean section & $0.51(0.36-0.73)^{\star *}$ & $0.67(0.50-0.89)^{\star *}$ & $1.17(1.00-1.37)$ & $1.19(1.00-1.43)$ \\
\hline$N$ & 865 & 865 & 703 & 546 \\
\hline
\end{tabular}

PBF - partial breast-feeding; EBF - exclusive breast-feeding; OR - adjusted odds ratio; $\mathrm{Cl}$ - confidence interval; HR - adjusted hazard ratio. ${ }^{\star} P<0.05,{ }^{\star \star} P<0.01$.

care, had given birth previously or had a Caesarean section.

Factors influencing PBF practice were examined using stepwise logistic regression analysis. Table 2 shows the results of the final model. The rate of $\mathrm{PBF}$ tended to be higher among mothers who had more education and among mothers who had more prenatal care. The adjusted ORs were 1.64 and 1.65, respectively. However, the rate tended to be lower among mothers who had a bluecollar job before marriage $(\mathrm{OR}=0.53)$ and among mothers who had a premature birth $(\mathrm{OR}=0.52)$. In particular, women who had a Caesarean section were approximately half as likely to initiate PBF as those who had a normal delivery $(\mathrm{OR}=0.51)$.

The median duration of breast-feeding among women who had initiated PBF was 12.0 weeks (Table 1). The logrank test revealed that the risk of terminating $\mathrm{PBF}$ early was significantly high when a mother had a Caesarean section. After adjusting for the other variables through stepwise Cox regression analysis, a Caesarean section increased the risk of weaning but was not statistically significant. The adjusted HR was $1.17(P=0.055)$ (Table 2$)$.

\section{Exclusive breast-feeding}

Compared with the EBF group, the non-EBF group had a higher proportion of mothers who had a blue-collar job before marriage, gave birth prematurely, received less prenatal care and had a Caesarean section (Table 1).

According to stepwise logistic regression analysis (Table 2), the rate of EBF tended to be higher among mothers who received more prenatal care $(\mathrm{OR}=1.38)$. However, both women who had a blue-collar job before marriage and women who had a Caesarean section tended not to initiate $\mathrm{EBF}(\mathrm{OR}=0.68$ and 0.67 , respectively).
The median duration of EBF was 8.0 weeks (Table 1) and longer among women who had less prenatal care and women who had a normal delivery. The log-rank test showed the amount of prenatal care and the delivery method were significant factors influencing the risk of cessation of EBF. After adjusting for the other variables, the amount of prenatal care was a significant determinant of the duration of EBF (Table 2). The women who had received more prenatal care were exposed to a higher risk of terminating EBF early $(\mathrm{HR}=1.24)$. Although not statistically significant $(P=0.051)$, the women who had a Caesarean section tended to stop EBF early $(\mathrm{HR}=1.19)$.

\section{Discussion}

According to the World Health Organization (WHO) definition of breast-feeding initiation rate ${ }^{7}$, in South Korea the rate was $81.3 \%$ in 2003 . Our additional analysis of the 2000 Korea National Fertility and Family Health Survey revealed the rate was $74.8 \%$ in 2000 . In addition, the rate was higher than those found in Hong Kong $(34 \%)^{8}$, France $(57 \%)^{9}$, The Netherlands and the USA (approximately $70 \%)^{10,11}$ and Singapore $(76 \%)^{12}$, although the rate was lower than those found in Australia and New Zealand $(90 \%)^{13,14}$, Lebanon $(95 \%)^{15}$ and rural Vietnam $(98 \%)^{16}$.

Given that the WHO has recommended continued breast-feeding up to 2 years of age and older ${ }^{17}$, the breast-feeding initiation in South Korea appears to be improving. However, the trend of breast-feeding for a very short period is of great concern. Kaplan-Meier survival estimates showed the rate of $\mathrm{EBF}$ was $30.2 \%$ at 3 months, $20.4 \%$ at 6 months and $7.5 \%$ at 12 months after delivery. At 4 months after delivery, the rate in South 
Korea $(26.8 \%)$ was much lower than that in Southeast Asia (49\%) and Iceland $(56 \%)^{18,19}$.

Our study confirmed that delivery by Caesarean section decreased the likelihood of breast-feeding ${ }^{16,20}$. Our results were also consistent with previous studies showing that once breast-feeding had begun, the delivery method no longer had any influence on the duration of breast-feeding $^{21,22}$. However, although not significant at the $5 \%$ level, Caesarean section was negatively related to breast-feeding duration $(P=0.055$ for PBF and $P=0.051$ for EBF). A possible reason for this trend in South Korea is that mothers delivering by Caesarean section believe the antibiotics contaminate breast milk. Another reason may be that the pain experienced prior to complete recovery from the surgery disrupts breast-feeding. Similarly, because the baby is often taken away after a Caesarean section, the attempts to initially breast-feed after delivery are discouraged. Another potential cause is that some characteristics that influence the duration of breast-feeding as well as delivery by Caesarean section were omitted in the models and generated an 'omitted-variable bias'. For example, in South Korea, for cosmetic or sexual reasons, some women may refuse breast-feeding and normal delivery because they believe breast-feeding practice deforms their breasts and having a normal delivery loosens the vagina. A further investigation of this trend may be necessary.

Surprisingly, the mothers who received more prenatal care tended to cease EBF earlier, compared with those with less or with no prenatal care. The result is in contrast to previous findings showing that prenatal care increased breast-feeding rate and its duration in the USA and Canada $^{23,24}$. There was no obvious explanation for this contradictory result. However, some medical professionals working at university hospitals have reported informally the prevalence in many local maternity units in South Korea of erroneous beliefs, such as that after 6 months breast-feeding is no more beneficial to an infant's health than simply providing water. Such attitudes, if widespread, could at least partly explain the observed trends. In order to determine which mothers would be more vulnerable to this erroneous belief, the effects of interaction terms in the Cox regression analyses were further investigated. Results showed that mothers who had more prenatal care and lower education level tended to terminate EBF early $(\mathrm{HR}=1.62, P<0.01)$.

In our dataset, there was no information on the women's employment status when they gave birth, so a variable regarding the women's employment status before marriage was included as a proxy. If a positive association is assumed between women's jobs before marriage and their jobs when they gave birth, an inference can be made that it is more difficult for women holding blue-collar jobs to initiate breast-feeding than either women holding while-collar jobs or housewives. Due to the difficulty of balancing the demands of work and breast-feeding ${ }^{12}$, many mothers holding blue-collar jobs may be discouraged from breast-feeding.

The South Korean government has enacted a few legal actions aimed at effective implementation of the International Code of Marketing of Breast-milk Substitutes recommended by the WHO. For example, the promotion of infant formula to the general public and the provision of free or low-cost supplies to health workers and healthcare facilities were prohibited in 1991 and the advertising of bottle-fed complementary foods, which are difficult to distinguish from formula, was prohibited in 2002. However, South Korea does not fully enforce the WHO code. For instance, South Korea does not prohibit the promotion of all breast-milk substitutes ${ }^{25}$. The Baby Friendly Initiative was introduced into South Korea's maternity services in 1993 by UNICEF Korea Baby Friendly, but by December 2006 only $1.8 \%$ of maternity units (57 out of 3126) had been accredited as Baby-Friendly maternity units $^{26,27}$.

In South Korea, infant formula companies proactively promote their products to health workers in maternity units and, regardless of the mothers' intentions, their infants often begin to be bottle-fed. Some companies invite health workers to classes on conception and newborn care and limit information concerning breast-feeding, while promoting their products. In January 2007, the Fair Trade Commission began to investigate two large infant formula companies on the suspicion that they had offered to loan a large amount of money to maternity hospitals at a low interest rate on the condition that the hospitals would feed their formula to newborns ${ }^{28}$.

One potential weakness in this study was the crosssectional study design, which may have led to some recall bias. As the survey was targeting mothers not health workers, clinical problems of infants, such as prematurity, growth retardation or illness, were not collected. The dataset included no information on mothers' employment status near delivery, which appears important to their breast-feeding practice.

In conclusion, despite an increased breast-feeding initiation in South Korea recently, newborns are being fed with formula and complementary food too early. Together with mother's education level and job pattern before marriage, factors such as the amount of prenatal care, delivery method and the baby's status at birth could affect the initiation of breast-feeding. The amount of prenatal care was significantly correlated with breast-feeding duration.

To promote breast-feeding, several strategies can be suggested. A systematic campaign and education regarding the importance and advantages of continued breast-feeding should be provided to the general public. In particular, health workers working in maternity units could have a considerable impact on increasing the duration of breast-feeding. The overuse and abuse of delivery by Caesarean section should be prohibited and women who have had a Caesarean section should be 
encouraged to breast-feed their infants. Supportive environments such as a nursery room at the worksite need to be built for working mothers, especially for those having blue-collar jobs. Maternity units should be encouraged to follow the guidelines of the Baby Friendly Initiative. The government should be urged to conduct evaluative research on the appropriateness of public policies to lessen the consumption of breast-feeding substitutes and, if necessary, should enforce a coordination of multi-faceted policies including the WHO code.

\section{Acknowledgements}

The views expressed in this article are those of the authors, and do not necessary reflect the policies of any organisation.

Sources of funding: There are no sources of funding.

Conflict of interest declaration: There are no conflicts of interest.

Authorship responsibilities: W.C. led the research project and participated in all phases of this study, including conceptualisation of the study, design and analysis. H.K. and C.-M.N. contributed to the data analysis and interpretation. All co-authors made substantial contributions to data analysis and interpretation and the writing of the manuscript.

\section{References}

1 National Statistical Office (NSO). Estimates of Population and Labor Indicators. Seoul: NSO, 2007.

2 Korea Institute for Health and Social Affairs. 2003 National Fertility and Family Health Survey Report. Seoul: Korea Institute for Health and Social Affairs, 2004.

3 Health Insurance Review Agency (HIRA). 2003 Caesarean Section Delivery Rates Report. Seoul: HIRA, 2003.

4 Kim SK, Cho AJ, Lee SS, Kim YK, Song IJ. 2000 National Fertility and Family Health Survey Report. Seoul: Korea Institute for Health and Social Affairs, 2000.

5 Park EO, Lee KS, Jang IS, June KJ. Breastfeeding and breastfeeding health behavior among first-time mothers. Korean Journal of Women's Health Nursing 2001; 7(3): 382-92.

6 Byun SJ. A study on performance of breastfeeding by employed mother. Korean Journal of Women's Health Nursing 1995; 1(2): 137-53.

7 World Health Organization (WHO). Indicators for Assessing Breast-feeding Practices. Geneva: WHO, 1991.

8 Leung GM, Ho LM, Lam TH. Breastfeeding rates in Hong Kong: a comparison of the 1987 and 1997 birth cohorts. Birth 2002; 29(3): 162-8.

9 Lathouwer SD, Lionet C, Lansac J, Body G, Perrotin F. Predictive factors of early cessation of breastfeeding: a prospective study in a university hospital. European Journal of Obstetrics, Gynecology, and Reproductive Biology 2004; 117(2): 169-73.

10 Bulk-Bunschoten AM, van Bodegom S, Reerink JD, Paskerde Jong PC, de Groot CJ. Reluctance to continue breastfeeding in The Netherlands. Acta Paediatrica 2001; 90(9): 1047-53.

11 Ryan AS, Wenjun Z, Acosta A. Breastfeeding continues to increase into the new millennium. Pediatrics 2002; 110(6): 1103-9.

12 Foo LL, Quek SJ, Ng SA, Lim MT, Deurenberg-Yap M. Breastfeeding prevalence and practices among Singaporean Chinese, Malay and Indian mothers. Health Promotion International 2005; 20(3): 229-37.

13 Essex C, Smale P, Geddis D. Breastfeeding rates in New Zealand in the first 6 months and the reasons for stopping. New Zealand Medical Journal 1995; 108(1007): 355-7.

14 Donath S, Amir L. Rates of breastfeeding in Australia by state and socio-economic status: evidence from the 1995 National Health Survey. Journal of Paediatrics and Child Health 2000; 36(2): 164-8.

15 Batal M, Boulghourjian C, Abdallah A, Afifi R. Breastfeeding and feeding practices of infants in a developing country: a national survey in Lebanon. Public Health Nutrition 2006; 9(3): 313-19.

16 Duong DV, Binns CW, Lee AH. Breast-feeding initiation and exclusive breast-feeding in rural Vietnam. Public Health Nutrition 2004; 7(6): 795-9.

17 World Health Organization (WHO). The Optimal Duration of Exclusive Breastfeeding: Report of an Expert Consultation. Geneva: WHO, 2002.

18 World Health Organization (WHO). WHO Global Data Bank on Breastfeeding. Geneva: WHO, 1996.

19 Thome M, Alder EM, Ramel A. A population-based study of exclusive breastfeeding in Icelandic women: is there a relationship with depressive symptoms and parenting stress? International Journal of Nursing Studies 2006; 43(1): 11-20.

20 Ever-Hadani P, Seidman DS, Manor O, Harlap S. Breast feeding in Israel: maternal factors associated with choice and duration. Journal of Epidemiology and Community Health 1994; 48(3): 281-5.

21 Mansbach IK, Greenbaum CW, Sulkes J. Onset and duration of breast feeding among Israeli mothers: relationships with smoking and type of delivery. Social Science \& Medicine 1991; 33(12): 1391-7.

22 Bruce NG, Khan Z, Olsen ND. Hospital and other influences on the uptake and maintenance of breast feeding: the development of infant feeding policy in a district. Public Health 1991; 105(5): 357-68.

23 Noel-Weiss J, Rupp A, Cragg B, Bassett V, Woodend AK. Randomized controlled trial to determine effects of prenatal breastfeeding workshop on maternal breastfeeding self-efficacy and breastfeeding duration. Journal of Obstetric, Gynecologic, and Neonatal Nursing 2006; 35(5): 616-24.

24 Bonuck KA, Trombley M, Freeman K, McKee D. Randomized, controlled trial of a prenatal and postnatal lactation consultant intervention on duration and intensity of breastfeeding up to 12 months. Pediatrics 2005; 116(6): 1413-26.

25 Ministry of Health and Welfare. Status of Implementation in WHO Member States: The International Code of Marketing of Breastmilk Substitutes. Seoul: Ministry of Health and Welfare, 2007.

26 Health Insurance Review Agency (HIRA). Statistics. Seoul: HIRA, 2007.

27 UNICEF Korea. Breastfeeding. Seoul: UNICEF Korea, 2007.

28 Kim TH. Connection between formula companies and hospitals. Medical Today, 11 January 2007. 